\title{
Breakdown of seamounts at the trench axis, viewed from gravity anomaly
}

\author{
By Gi-Churl ShiN*) and Yoshibumi TomodA, M. J. A.
}

(Communicated March 12, 1998)

\begin{abstract}
The Daiichi-Kashima seamount in the Japan trench and a wedge shaped seamount in the Ogasawara trench are good examples that the seamount breaks down and sink at the axis of the trench. We estimated subterranean structure of these seamounts using gravity anomaly and topography, and proposed a model. Disappearance of a deep root of the mountain in the upper mantle supporting the mass of the mountain, can explain the phenomena. It is suspected that main reason of disappearance of the root is due to compression caused by the bending of the plate near the trench.
\end{abstract}

Key words : Seamount; trench; gravity anomaly.

Introduction: interaction between trench and continent, submarine rise, or seamount. Small continents, submarine rises or seamounts on the sea floor move with the plate, and they arrive to the trench at the margin of a continent or island arc. A kind of collision takes place there. When topography is supported by the buoyancy caused by density difference between the crust and the mantle and Airy's isostasy is achieved, the collision takes place. Then, the continent does not sink at the trench as seen in the collision between the Eurasia continent and continent of India, or that between the Izu peninsula and the island arc of Japan.

In the region of a junction between the Izu and the main land of Japan, crustal structure of both blocks mixes each other. According to the explosion seismology, the crust is mixing in such way that the layer of heavy density occupies the lower structure and the layer of light density occupies the upper structure. A numerical simulation at the junction area gives the same results. ${ }^{1)}$ The large submarine rises such as Shatsuky Rise in the north west Pacific or Ontong Java Plateau north of the Solomon Islands have thick crust of about $30 \mathrm{~km}$. When these submarine continents arrive at the trench, they could not descend and the trench axis jumps toward seaward of it. ${ }^{2)}$ On the other hand, a small seamount arrived at the trench axis breaks down and sinks with the oceanic lithosphere. These facts show that behavior of the seamount or submarine rise or the small continent at the convergence of the plate, depend on the crustal structure. When the mass of the topography

*) Hyundai institute of construction technology, San 1-1, Mabuk-Ri, Goosung-Myun, Yongin-si, Kyunggi-Do, 449-910, Korea. is supported by the root of the continent, it becomes an accretion of the continent. On the other hand the topography would break down, when a buoyancy in the upper mantle supports the mass.

There are good examples of sinking seamounts at the trench in the West Pacific. The one is the Daiichi-Kashima seamount situated at the junction of the Japan Trench and the Izu-Ogasawara Trench (Fig. 1a). The other is the wedge shaped seamount (abbreviation used in the present paper) north of the junction point of the Izu-Ogasawara and the Mariana Trench (Fig. 1b). Fig. 1 shows bottom topography in these regions, drawn with approximately same horizontal scale for easy comparison.

In the present paper we studied these two regions using the relation between gravity anomaly and the topography. We also studied processes of the breakdown of the seamount or ridge from the subterranean structure. Our basic philosophy is that the principle of the Isostasy is a leading principle and the subterranean structure controls all behavior such as the breakdown of the topography.

Daiichi-Kashima seamounts. The DaiichiKashima seamount was discovered as a shallow part of the Japan trench in 1934. The following survey showed that the shallow region is a seamount and named Kashima. In 1980, Mogi examined the data and interpreted that a normal fault running from northeast to southwest divides a seamount into two parts. He also interpreted that the west part of it is now sinking at the trench axis. ${ }^{3)}$ We used a detailed map of topography measured by a multi-narrow beam echo sounder and records of sedimentary structure measured by a seismic prolifer. ${ }^{4}$ The gravity survey in the area was carried out from $1960-1983$ and $5^{\prime} \times 5^{\prime}$ mesh data 

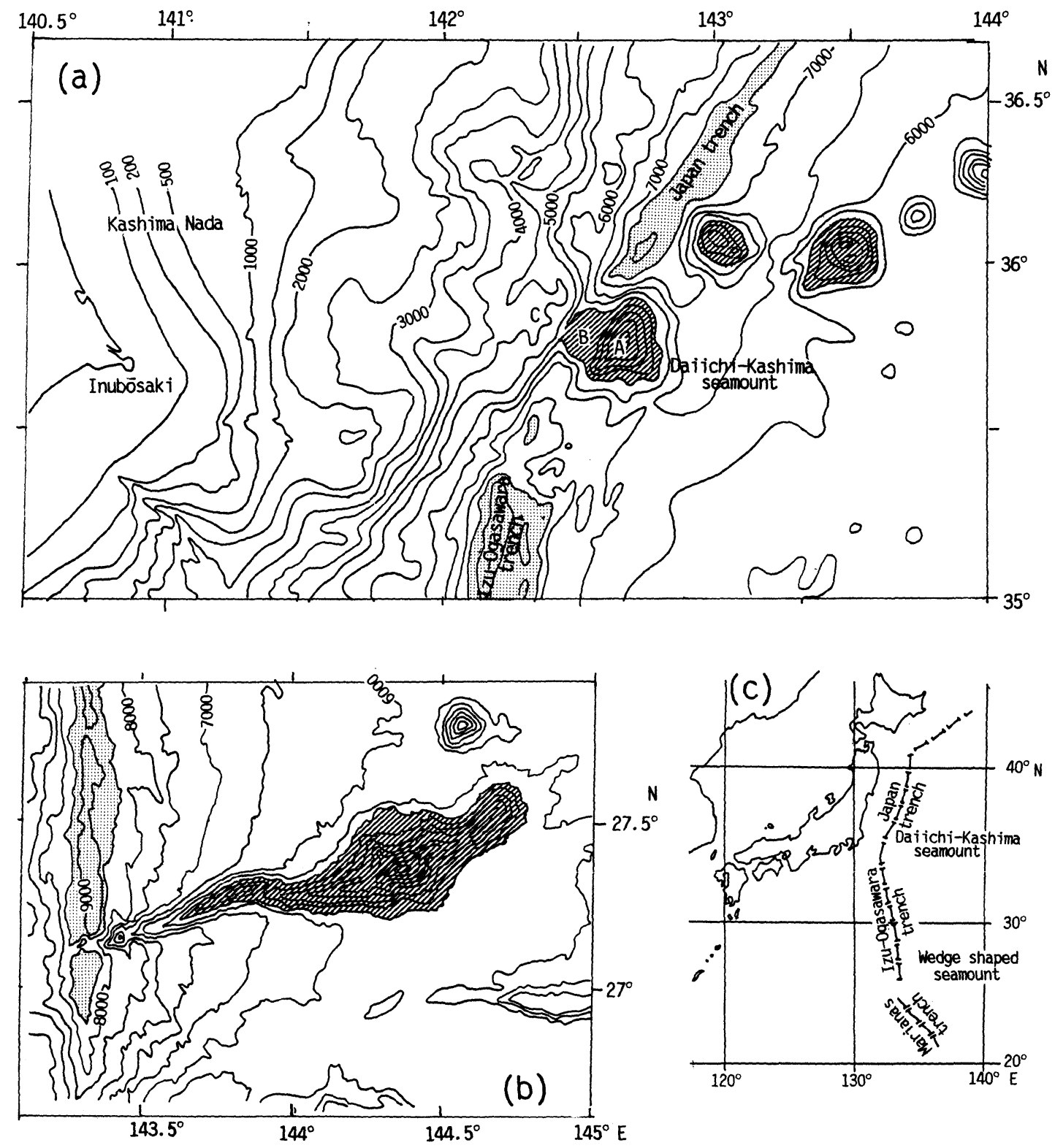

Fig. 1. Bottom topography of the Daiichi-Kashima seamount (a) and the wedge shaped seamount (b). The interval of contour is $500 \mathrm{~m}$ and the maps are shown with same horizontal scale. (c) shows the location of the two seamounts.

are available. ${ }^{5)}$ We did not use satellite gravity data because we found large discrepancy between the surface ship gravity. Results of study for the seamount are briefly summarized as followings.

a) Difference in height of the body of the mountain at the trench axis and height at the seaward of the trench axis is proportional to each height. The bottom topographies parallel to the trench axis are shown in Fig. 2. Though height difference between the normal oceanic basin and the trench axis is less than $1000 \mathrm{~m}$, difference at the top region is about $2000 \mathrm{~m}$. This means that the seamount sank more than $1000 \mathrm{~m}$ deeper than the normal basin. This seems to show that a buoyancy supporting the mass of the mountain disappeared and it sank for isostatic equilibrium.

b) We calculated the density of two parts of the seamount, from the relation between free air gravity anomaly and bottom topography of shorter wave length. The best density is given by $\Sigma\left(G_{\text {obs }}-G_{\text {cal }}\right)^{2} \rightarrow$ min., where $G_{\text {obs }}$ and $G_{\text {cal }}$ respectively represent free air gravity anomaly and calculated gravity for a given density of the topography. Density at the broken region (region B, Fig. 1a) and that at the seaward of it (region A, Fig. 1a) has the 

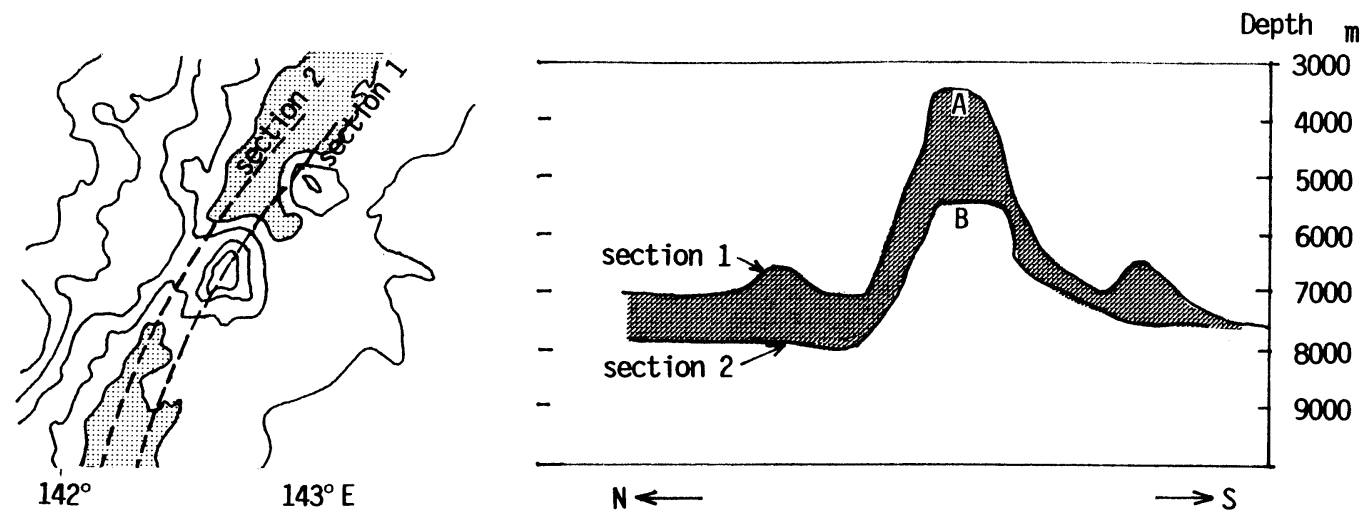

Fig. 2. Two profiles show topography of the Daiichi-Kashima seamount parallel to the trench axis. Section 1 shows the topography seaward of the seamount. The section 2 shows the topography along the trench axis. Though difference between the normal basin and the trench axis is less than $1000 \mathrm{~m}$, the difference in the crests of east part (A in Fig. 1a) and west part (B in Fig. 1a) is about $2000 \mathrm{~m}$.
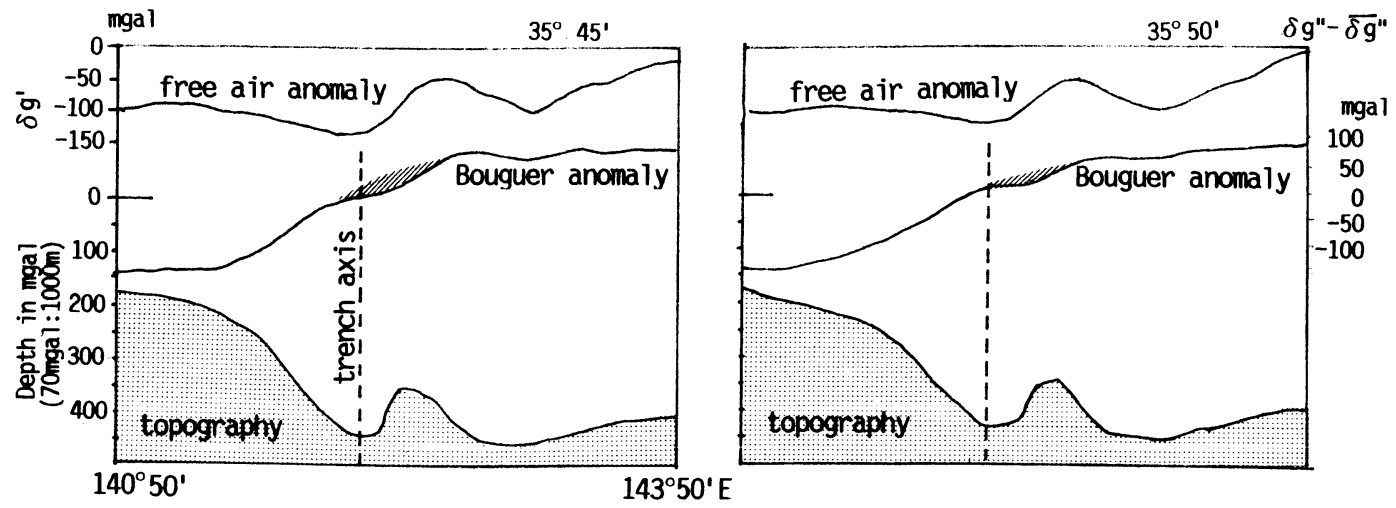

Fig. 3. Profile of free air gravity anomaly, bottom topography and Bouguer anomaly at latitude $35^{\circ} 40^{\prime}$ and $35^{\circ} 45^{\prime} \mathrm{N}$. $\delta \mathrm{g}^{\prime}$ : Free air gravity anomaly, $\delta \mathrm{g}^{\prime \prime}$ : Bouguer anomaly, $\overline{\delta \mathrm{g}^{\prime \prime}}$ : means of Bouguer anomaly. Maximum free air gravity anomaly accompanied by the seamount lies at landward of the seamount. Locally negative Bouguer gravity anomaly (hatched area in the Figure) exists beneath the seamount.

same value. We also calculated the density of small topographic high just east of the seamount landward of the trench axis (region C, Fig. 1a). Given density at the region $\mathrm{A}, \mathrm{B}$ and $\mathrm{C}$ are respectively $2.63,2.63$ and $2.27 \mathrm{gr} / \mathrm{cm}^{3}$.

c) Density landward topographic high corresponds to the density of the sedimentary layer. This means that the small topographic high east of the seamount beyond the trench axis (region C) is not composed by an accretion of the main part of the seamount. We suppose that the sediment originates in the island arc, or in a surface layer of the oceanic basin that did not sink with the plate. A numerical simulation also shows that it is difficult for the sediment of low density to sink with plate.

d) To see whether we can recognize a root of the seamount, we made profiles of free air gravity anomaly, Bouguer anomaly, and bottom topography along the $5^{\prime}$ interval of latitude. Examples are shown in Fig. 3. It seems not easy to clearly identify the root of the seamount. However locally negative Bouguer gravity anomaly (shown by the hatching) may suggest the existence of the root, or the lower part of the mountain dropped in the upper mantle.

e) According to the sedimentary structure observed by acoustic method, the structure is laminated, and there found no disturbances caused by the collison of the seamount. If the movement of the mountain on the traveling plate is blocked by the collision with the seaward of the island arc of Japan, disturbed sedimentary layer should be observed behind the seamount. However, we could not recognize such characteristics in the acoustic records.

f) As shown in Fig. 4, seismicity in the year from 1926 to 1988 around the Daiichi-Kashima and the other seamounts is not active compared with the other regions. 
The authors suspect that this is caused by a high temperature low density within the lithosphere, that is, subterranean dynamical characteristic beneath the seamount is deformable compared with the other normal area, and suppress the activity of earthquakes. This condition produces the different origin of buoyancy than the density contrast between the crust and the mantle.

Analysis for the wedge-shaped ridge. A wedge shaped small seamount lies at the east of the Izu-

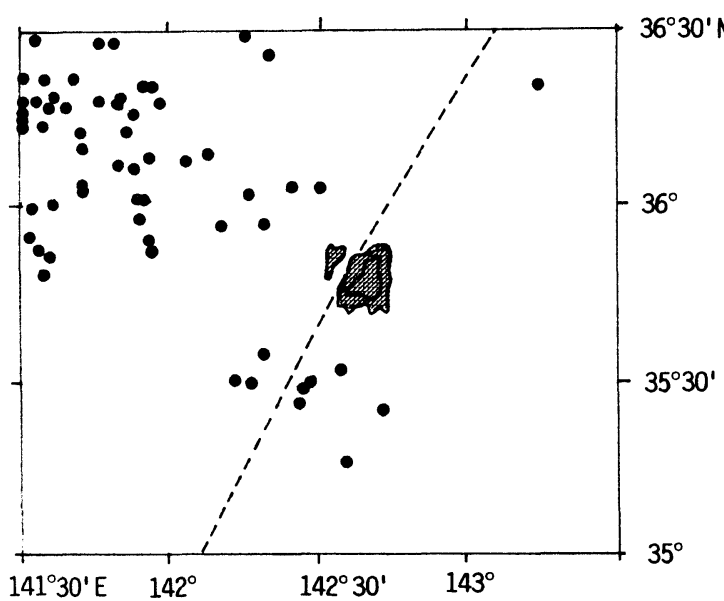

Fig. 4. Seismic activities near and around the Daiichi-Kashima seamount. The circles show the epicenter of the Earthquakes larger than $\mathrm{M}=5.5$ that occurred from 1973-1987. Low seismicity around the mountain suggests the existence of a deformable material.
Ogasawara trench, approximately perpendicular to the axis of the trench. The east end of the seamount seems to sink at the trench. Several normal faults parallel to the trench axis represent the subduction of both the seamount and the surrounding oceanic basin (Fig. 1b). The region is a good example to study how the ridge breaks down according as it arrives near the axis of the trench. We assumed the Airy's isostasy and calculated the depth of compensation of isostasy at three sections shown in Fig. 5. As for the data of the wedge shaped seamount, we used a recent topographic data given by multi-narrow echo sounder and surface ship gravity data measured by Hydrographic Department of Japan. ${ }^{6)}$

If $\mathrm{G}_{\mathrm{d}}(\omega)$ represents gravity anomaly of particular wave number $\omega(\omega=2 \pi / \lambda, \lambda$ represents wave length) caused by a topography at depth $\mathrm{d}$. And if $\mathrm{G}_{\mathrm{T}}(\omega)$ represents gravity anomaly viewed at depth $T$ caused by structure at the depth $\mathrm{T}$, then condition for the isostatic equilibrium is given by

$$
\mathrm{G}_{\mathrm{d}}(\omega)+\mathrm{G}_{\mathrm{T}}(\omega)=0 .
$$

Gravity anomaly at the sea surface $G_{\text {cal }}$, caused by the structure is given by the following formula,

$$
\begin{aligned}
\mathrm{G}_{\text {cal }} & =\mathrm{G}_{\mathrm{d}} \exp (-\omega \mathrm{d})+\mathrm{G}_{\mathrm{T}} \exp (-\omega \mathrm{T}) \\
& =\mathrm{G}_{\mathrm{d}} \exp (-\omega \mathrm{d})-\mathrm{G}_{\mathrm{d}} \exp (-\omega \mathrm{T}) .
\end{aligned}
$$

The depth of compensation $T$ is given by $\Sigma\left(\mathrm{G}_{\mathrm{cal}}-\mathrm{G}_{\mathrm{obs}}\right)^{2}$ $\rightarrow$ min., where $G_{\text {obs }}$ represents observed free air anomaly at the sea surface.

The compensation depth obtained at three sections in

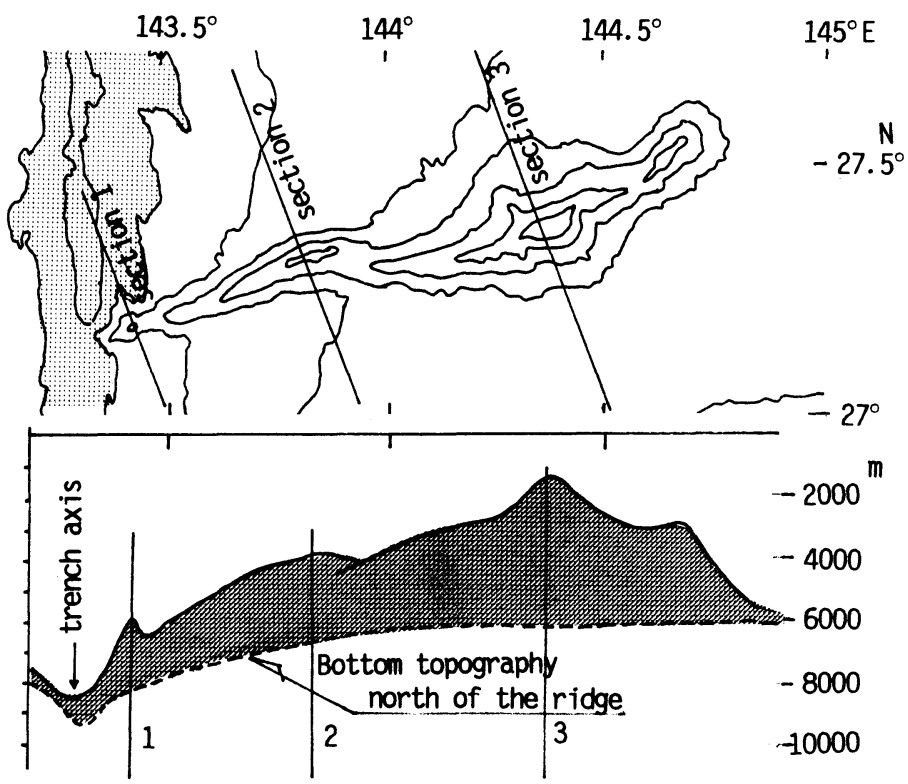

Fig. 5. Profiles show height connecting the summits of the wedge shaped seamount and the bottom topography north of the seamount. The depth of compensation was calculated for three sections shown by section 1 , section 2 and section 3 and is respectively $11,23,33 \mathrm{~km}$. 
Fig. 5 are respectively 11,23 and $33 \mathrm{~km}$ from the sea surface. In the Figure, we showed a profile of topography connecting the summits of the seamount, and the depth parallel to the crest about $50 \mathrm{~km}$ north of it. The depth of compensation near the trench axis (section 1), seems too shallow, when water depth at there is about $8 \mathrm{~km}$. We suppose that the accuracy of gravity value is not so high because the anomaly due to the topography is about 10 mgal, or it is due to inaccuracy in assumption of twodimension model. The result shows that the depth of isostasy becomes shallow according to the distance from the trench axis.

To understand the geophysical meaning of change in the compensation depth, we examined 'two layer model'. This means that, the mass of the seamount is supported by a buoyancy caused at two boundaries of different depth. One boundary is between the crust and mantle, and the other is deeper part of the mantle where a low density material due to a hot spot exists. Then, following formula represents condition for the isostatic equilibrium.

$$
\mathrm{G}_{\mathrm{d}}(\omega)+\mathrm{G}_{\mathrm{D}}(\omega)+\mathrm{G}_{\mathrm{H}}(\omega)=0 .
$$

Where, $C_{d}(\omega),(\omega=2 \pi / \lambda)$, denotes gravity effect viewed at the depth $\mathrm{d}$ caused by a bottom topography at depth $d, G_{D}(\omega)$ denotes gravity effect at the depth $\mathrm{D}$ (depth of the Moho), $\mathrm{G}_{\mathrm{H}}(\omega)$ denotes gravity effect of low density material in the mantle at the depth $\mathrm{H}$.

Calculated gravity anomaly at the sea surface $\mathrm{G}_{\mathrm{cal}}$ is given by,

$\mathrm{G}_{\mathrm{cal}}=\mathrm{G}_{\mathrm{d}} \exp (-\omega \mathrm{d})+\mathrm{G}_{\mathrm{D}} \exp (-\omega \mathrm{D})+\mathrm{G}_{\mathrm{H}} \exp (-\omega \mathrm{H})$.

When $\mathrm{k}$ represents the ratio between contribution of the buoyancy at the depth $\mathrm{D}$ (Moho), and the contribution at deeper part of the mantle, the formula above becomes as followings,

$\mathrm{G}_{\text {cal }}=\mathrm{G}_{\mathrm{d}} \exp (-\omega \mathrm{d})-\mathrm{kG}_{\mathrm{d}} \exp (-\omega \mathrm{D})-(1-\mathrm{k}) \mathrm{G}_{\mathrm{d}} \exp (-\omega \mathrm{H})$.

On the other hand, in single layered model mentioned above,

$$
\mathrm{G}_{\mathrm{cal}}=\mathrm{G}_{\mathrm{d}} \exp (-\omega \mathrm{d})-\mathrm{G}_{\mathrm{d}}(-\omega \mathrm{T}) .
$$

Then the value of $\mathrm{k}$ is given from $\mathrm{T}, \mathrm{D}$ and $\mathrm{H}$ by the following formula,

$$
\begin{aligned}
\mathrm{k}= & \{\exp (-2 \pi \mathrm{T} / \lambda)-\exp (-2 \pi \mathrm{H} / \lambda)\} / \\
& \{\exp (-2 \pi \mathrm{D} / \lambda)-\exp (-2 \pi \mathrm{H} / \lambda)\} .
\end{aligned}
$$

Predominant wave length at the section 2 is $34-36 \mathrm{~km}$, and the value of $k$ is 0.09 , when buoyancy at the deeper place is $33 \mathrm{~km}$ that is equal to the depth of compensation of section 3.

This means that buoyancy contribution at the Moho surface is about $9 \%$ of buoyancy at the depth of $33 \mathrm{~km}$. The value of $\mathrm{k}$ is not sensitive to the depth $\mathrm{H}$ when $\mathrm{H}$ is deep compared with the predominant wave length. For example the value of $\mathrm{k}$ is 0.1 when the depth of $\mathrm{H}$ is $50 \mathrm{~km}$. As mentioned before, buoyancy at the Moho supports the mass of the ridge at section 1 . The above result seems to show that buoyancy contribution at the Moho surface becomes large according as the seamount approaches to the trench axis.

Summary: processes of breakdown of the sea mount. Seismicity seaward of the trench near the Daiichi-Kashima seamount is inactive though its location is near the seismically active region of the Kashimanada (Fig. 1a). This seems to suggest the existence of a high temperature low density region concerned to the origin of the seamount.

Topography profiles of the east part of the Kashima seamount and the west part (descended part of the seamount), show that amount of sinking is proportional to the height of the mountain. This suggests that the root of the mountain disappeared and the topography changed to achieve isostatic equlibrium.

Bouguer gravity anomaly parallel to latitude shows locally negative value at the seamount. The free air gravity anomaly does not correspond to the maximum height of the seamount. This means that the isostatic equilibrium is not achieved as a whole. At the present stage of interpretation, it is not easy to conclude that the negative Bouguer anomaly represents dropped body that had been a part the seamount.

From the depth of origin of buoyancy on the wedge shaped seamount, we can estimate a change in height of topography. When the Airy's isostasy is achieved, the thickness of the root of the crust becomes about three times of height of the topography if density of sea water, crust, and upper mantle, is respectively $1.03,2.7$ and 3.3 $\mathrm{gr} / \mathrm{cm}^{3}$. Therefore, the height would become $3 \mathrm{~km}$, three times of the present height, if a buoyancy at deep part in the upper mantle exists near the trench and support the topography (section 1 in Fig. 5). On the other hand, in topography of the section 2, the height becomes $30 \%$ higher than the present situation. This is a reconstruction of topography of the wedge shaped seamount. Though, the height of the seaward of the ridge is about $3000 \mathrm{~m}$ higher than its east part, paleo-height of the crest of the seamount was approximately the same when it had been far from the trench axis!

Recently the author presented a model that mass of the seamount is supported by buoyancy, at both the Moho surface and the boundary between the lithosphere and the asthenosphere. ${ }^{7)}$ Main density boundaries of subterranean structure are these two boundaries. We also presented a model that the buoyancy at the later density boundary varies according to the age of the seamount. ${ }^{8)}$ Though we 
[Vol. 74(B),

not yet examine petrological phase change, compression due to the bending of thick lithosphere would dissipate the buoyancy at the deeper part beneath the seamount as cooling process does in the aged seamount.

\section{References}

1) Matsumoto, T., and Tomoda Y. (1984) J. Phy. Earth 32, 137-142.

2) Tomoda, Y., and Fujimoto, H. (1983) Accretion Tectonics in the Circum-Pacific Regions. Terra Scientific Publishing Company (TERAPUB), Tokyo, pp. 319-331.

3) Mogi, A., and Nishizawa, K. (1980) Proc. Japan Acad. 56B,
257-259.

4) Kaiko I Research Group (1986) Data atlas of Franco-Japanese Kaiko Project I. Univ. Tokyo Press.

5) Fujimoto, H., and Nakakuki, T. (1991) Proceeding of the symposium on the present state and future in the study of Geoid (Abstract).

6) Ohara, Y., Kasuga, S., Okino, K., and Kato, Y. (1997) Survey Maps Philippine Sea Structures, Eos, Pransactions, American Geophysical Union, 78, no. 48, p. 555.

7) Tomoda, Y., and Fujimoto, H. (1996) Proc. Japan Acad. 72B, 39-43.

8) Tomoda, Y., and Akiyama, A. (1995) Physics of the Earth and Planetary Interiors 92, 17-23. 